\title{
Advanced oxidation protein products induce cardiomyocyte death via Nox2/Rac1/superoxide-dependent TRAF3IP2/JNK signaling
}

\author{
Anthony J. Valente ${ }^{1}$, Tadashi Yoshida ${ }^{2}$, Robert A. Clark ${ }^{1}$, Patrice Delafontaine ${ }^{2}$, Ulrich \\ Siebenlist ${ }^{3}$, and Bysani Chandrasekar ${ }^{2,4,{ }^{*}}$ \\ ${ }^{1}$ Medicine, University of Texas Health Science Center and South Texas Veterans Health Care \\ System, San Antonio, TX 78229 \\ ${ }^{2}$ Heart and Vascular Institute, Tulane University School of Medicine, New Orleans, LA 70112 \\ ${ }^{3}$ Laboratory of Immunoregulation, NIAID/NIH, Bethesda, MD 20892 \\ ${ }^{4}$ Research Service, Southeast Louisiana Veterans Health Care System, New Orleans, LA 70161
}

\section{Abstract}

Advanced oxidation protein products (AOPPs) are formed during chronic oxidative stress as a result of reactions between plasma proteins and chlorinated oxidants. Their levels are elevated during various cardiovascular diseases. Since elevated AOPPs serve as independent risk factors for ischemic heart disease, and cardiomyocyte death is a hallmark of ischemic heart disease, we hypothesized that AOPPs will induce cardiomyocyte death. AOPPs-modified mouse serum albumin (AOPPs-MSA) induced significant death of neonatal mouse cardiomyocytes that was attenuated by Receptor for Advanced Glycation End Products (RAGE), but not CD36 knockdown. Notably, TRAF3 interacting protein 2 (TRAF3IP2; also known as CIKS or Act1) knockdown blunted AOPPs-induced apoptosis. AOPPs-MSA stimulated Nox2/Rac1-dependent superoxide generation, TRAF3IP2 expression, and TRAF3IP2-dependent JNK activation. The superoxide anion generating xanthine-xanthine oxidase system and hydrogen peroxide both induced TRAF3IP2 expression. Further, AOPPs-MSA induced mitochondrial Bax translocation and release of cytochrome $c$ into cytoplasm. Moreover, AOPPs-MSA suppressed anti-apoptotic Bcl-2 and Bcl-xL expression. These effects were reversed by TRAF3IP2 knockdown or forced expression of mutant JNK. Similar to its effects in neonatal cardiomyocytes, AOPPs-MSA induced adult cardiomyocyte death in part via TRAF3IP2. These results demonstrate for the first time that AOPPs induce cardiomyocyte death via Nox2/Rac1/superoxide-dependent TRAF3IP2/ JNK activation in vitro, and suggest that AOPPs may contribute to myocardial injury in vivo. Thus TRAF3IP2 may represent a potential therapeutic target in ischemic heart disease.

(C) 2013 Elsevier Inc. All rights reserved.

*To whom correspondence should be addressed: Bysani Chandrasekar, DVM. Ph.D., Heart and Vascular Institute, Tulane University School of Medicine, 1430 Tulane Avenue, SL-48, New Orleans, LA 70112, Tel.: 504-988-3034, bchandra@tulane.edu.

Publisher's Disclaimer: This is a PDF file of an unedited manuscript that has been accepted for publication. As a service to our customers we are providing this early version of the manuscript. The manuscript will undergo copyediting, typesetting, and review of the resulting proof before it is published in its final citable form. Please note that during the production process errors may be discovered which could affect the content, and all legal disclaimers that apply to the journal pertain.

Disclosures

None declared 


\section{Keywords}

AOPPs; TRAF3IP2; oxidative stress; cell death; myocardial injury

\section{Introduction}

Reactive oxygen species (ROS) are continuously generated under normal physiological conditions, and converted to non-toxic metabolites by the cellular antioxidant defense systems. While low levels of ROS regulate various signal transduction pathways involved in cell survival, differentiation and growth, chronically elevated production of ROS beyond the antioxidant capacity of the tissue results in oxidative stress, generation and accumulation of deleterious oxidatively modified lipids, proteins, carbohydrates, and nucleic acids, and tissue injury [1-4]. Several chronic inflammatory diseases, including diabetes mellitus, atherosclerosis, and chronic kidney disease, are characterized by increased oxidative stress, and enhanced tissue and systemic levels of oxidized lipids, and tissue deposition of immune complexes containing oxidized lipids and antibodies [5-11]. These diseases are also characterized by the accumulation of dityrosine-containing advanced oxidation protein products (AOPPs) in plasma and tissues [5-11].

AOPPs are formed as a result of reactions between plasma proteins and chlorinated oxidants (e.g., hypochlorous acid, $\mathrm{HOCl}$ ) [9]. AOPPs are mainly carried by albumin in the circulation. Like advanced glycation end products (AGEs), AOPPs signal via the receptor for AGEs (RAGE) in endothelial cells [10], and induce endothelial dysfunction. AOPPs can also induce podocyte death via RAGE [11]. In contrast, AOPPs upregulate the expression levels of almost all components of the renin-angiotensin system (RAS) and enhance angiotensin-converting enzyme (ACE) activity in cultured proximal tubular epithelial cells via the scavenger receptor CD36 [12], suggesting that AOPPs can signal via different receptors in a cell type-specific manner. AOPPs also inhibit proliferation and differentiation of rat osteoblast-like cells in part via NF- $\mathrm{kB}$ activation [13]. However, whether AOPPs affect cardiomyocyte survival has not been reported.

In addition to being products of chronic oxidative stress, AOPPs can also trigger oxidative stress. In earlier reports, AOPPs have been shown to stimulate ROS generation from a variety of cells through a mechanism strongly suggesting a role for the Nox family of NADPH oxidases [11, 14, 15]. Cardiomyocytes express principally the Nox 2 and Nox4 isoforms of NADPH oxidase, which display differential sub-cellular localization $[3,4,16]$. While Nox 2 is inducible, predominantly located in the plasma membrane, and generates mainly superoxide, Nox 4 is constitutively active, found in nucleus, ER, and mitochondria, and its usual measurable product is hydrogen peroxide. There is evidence that the ROS generated via NADPH oxidases can perpetuate their own production via a feed-forward mechanism, and contribute to chronic oxidative stress and cell injury.

NF- $\kappa \mathrm{B}$ and AP-1 are two ubiquitously expressed redox-sensitive transcription factors. In cardiomyocytes, activation of NF- $\mathrm{KB}$ has generally been shown to activate cell survival pathways [17], whereas activation of AP-1 is associated with cell injury or death [18]. Under basal conditions NF- $\mathrm{\kappa B}$, comprising mainly of the p50 and p65 heterodimer, is retained in the cytoplasm by virtue of its binding to an inhibitory molecule IкB. Oxidative stress promotes I $\mathrm{KB}$ phosphorylation and subsequent degradation, resulting in translocation of released NF- $\kappa$ B to the nucleus and induction of $\kappa B$-dependent gene transcription [19]. Phosphorylation of IאB is mediated by the IKK signalosome comprising of the catalytic subunits IKKa and IKK $\beta$, and the regulatory subunit IKK $\gamma$ [19]. AP-1, comprising mainly 
of c-Fos and c-Jun heterodimers, is activated by JNK [20]. Upon phosphorylation by JNK, c-Jun translocates to the nucleus and induces AP-1-dependent gene transcription [20].

TRAF3IP2 is a novel adapter molecule [21, 22] that ubiquitinates TRAF6 at Lys63 [23], and activates IKK/NF- $\times$ B and JNK/AP-1-dependent signaling [21-23]. Its critical role in interleukin (IL)-17 mediated autoimmune and inflammatory signaling has been described [24]. IL-17A has recently been shown to play a role in myocardial ischemic injury and induce cardiomyocyte death [25]. Since TRAF3IP2 physically associates with IL-17RA, and as IL-17A signals mainly via IL-17RA, it is plausible that TRAF3IP2 might contribute to IL-17A induced cardiomyocyte death. Since AOPPs suppress cell proliferation via activation of NF- $\mathrm{BB}$ [13] and induce cell death [11], and as systemic AOPPs levels are increased in various chronic inflammatory diseases with increased oxidative stress, and contribute to cardiovascular diseases [26], we hypothesized that AOPPs induce cardiomyocyte death in a TRAF3IP2-dependent manner.

Using pathophysiological concentrations of AOPPs, here we demonstrate for the first time that AOPPs-modified mouse serum albumin (AOPPs-MSA) induces significant death of neonatal and adult cardiomyocytes, and this effect is reversed by TRAF3IP2 knockdown or gene deletion. Further, in neonatal cardiomyocytes, TRAF3IP2 knockdown blocks AOPPsMSA-induced JNK phosphorylation, c-Jun activation, Bax translocation to mitochondria, and caspase- 3 activation, and restores the anti-apoptotic Bcl-2 and Bcl-xL expression. These results demonstrate that AOPPs exert potent pro-apoptotic effects on cardiomyocytes, and TRAF3IP2 is a critical player in this response. These results suggest that enhanced AOPPs found during conditions of chronic oxidative stress, may exert pathobiological effects in the heart via TRAF3IP2, and targeting TRAF3IP2 could potentially blunt myocardial injury.

\section{Materials and methods}

\section{Materials}

LPS-EB Ultrapure (\#tlrl-3pelps) was purchased from InvivoGen (San Diego, CA).

Polymyxin B sulfate, fatty acid and globulin free mouse serum albumin, xanthine, xanthine oxidase, bovine liver catalase, hydrogen peroxide, $\mathbf{a}$-sarcomeric actin antibodies, $\mathbf{a}$-tubulin polyclonal antibodies, and lentiviral shRNA for GFP (SHC005V), TRAF3IP2 shRNA (TRCN0000105990), RAGE (TRCN0000071743) and CD36 (TRCN0000066518) were all purchased from Sigma-Aldrich (St. Louis, MO). Polyclonal anti-TRAF3IP2 antibodies were purchased from IMGENEX (\#IMG-563; San Diego, CA). Goat anti-mouse RAGE neutralizing antibodies (\#AF1179; $20 \mu \mathrm{g} / \mathrm{ml}$ for $2 \mathrm{~h}$ ) and normal goat IgG (\#AB-108-C) were purchased from R \& D Systems (Minneapolis, MN). CD36 blocking antibodies (\#ab23680; $20 \mu \mathrm{g} / \mathrm{ml}$ for $2 \mathrm{~h}$ ) were from Abcam (Cambridge, MA). Anti-mitochondrial protein $\beta$-subunit of complex V (V- $\beta$; A21351) antibodies and all cell culture supplies were from Invitrogen Corporation (Carlsbad, CA). Affinity-purified rabbit polyclonal antibodies that detect the active (cleaved) p17 form of caspase-3, but not the p35 precursor form (\#AB3623), and antibodies against gp91phox (Nox2; \#07-024), GAPDH (\#MAB374) and TRAF6 (\#04-451) were purchased from Millipore (Billerica, MA). Antibodies to caspase-3 (\#9662 and 9664), c-Jun (\#9165), phospho-c-Jun (Ser63; \#9261), JNK (\#9252), phosphoJNK (Thr183/Tyr185; \#9251), a-tubulin (\#2144) and Lamin A/C (\#2032) were from Cell Signaling Technology, Inc. (Beverly, MA). The polyclonal anti-caspase-3 antibodies (\#9662) detect both the full-length $(35 \mathrm{kDa})$ and cleaved active forms $(17 / 19 \mathrm{kDa})$, and the monoclonal antibodies (\#9664) detect only the cleaved forms. DPI (\#300260; $10 \mu \mathrm{M}$ in DMSO for $30 \mathrm{~min}$ ), SP600125 (20 $\mu \mathrm{M}$ for $30 \mathrm{~min}$ ), and their diluent (DMSO) were purchased from EMD4Biosciences (San Diego, CA). Caspase-3 activity assay kit was obtained from EMD Chemicals (Gibbstwon, NJ). The caspase-3 inhibitor Z-DEVD-fmk, pan-caspase inhibitor Z-VAD-fmk, and the negative control Z-FA-fmk were obtained from 
Enzyme Systems Products (Livermore, CA), and were used at $50 \mu \mathrm{M}$ in DMSO.

QCL-1000 ${ }^{\mathrm{TM}}$ Endpoint chromogenic Limulus amoebocyte lysate assay (\#50-647U) was purchased from Lonza. Enhanced chemiluminescence detection kit was from Amersham Pharmacia Biotech. At the indicated concentrations and for the duration of treatment, the pharmacological inhibitors failed to modulate cardiomyocyte morphology, viability or adherence to culture dishes (data not shown).

\section{Preparation of AOPPs-MSA}

AOPPs-MSA was prepared as previously described $[27,28]$ by exposing fatty acid, globulin, and carbohydrate free MSA $(100 \mathrm{mg} / \mathrm{ml})$ to HOCl/PBS $(100 \mu \mathrm{M})$ for 30 minutes at room temperature and dialyzed for $16 \mathrm{~h}$ against three changes of PBS. AOPPs comprise of several chromophores, including pentosidine, carbonyls, and proteins cross-linked by dityrosine, which shows absorbance at a wavelength of $340 \mathrm{~nm}$ [29]. In that study, Capeillere-Blandin, et al. reported that the chromophore that is absorbing at $340 \mathrm{~nm}$ matches that of pentosidine [29]. To quantify AOPPs concentration, $200 \mu 1$ of AOPPs-MSA or MSA in PBS were mixed with $20 \mu 1$ of glacial acetic acid, and measured at $340 \mathrm{~nm}$ in a SPECTRAmax PLUS microplate reader. A standard curve was generated using $200 \mu \mathrm{l}$ of chloramine-T solution ( 0 to $100 \mu \mathrm{M}), 10 \mu \mathrm{l}$ of $1.16 \mathrm{M}$ potassium iodide, and $20 \mu \mathrm{l}$ of glacial acetic acid. The contents of AOPPs in the stock AOPPs-MSA were $\sim 260 \mu \mathrm{M}$ versus $11 \mu \mathrm{M}$ in native MSA. The concentrations of dityrosine were $9.1 \mu \mathrm{M}$ versus $0.57 \mu \mathrm{M}$, respectively, and those of carbonyls were $18,840 \mu \mathrm{M}$ versus $89 \mu \mathrm{M}$, respectively, and were quantified as previously described [9]. MSA and AOPPs-MSA contained less than $0.02 \mathrm{EU} / \mathrm{ml}$ of endotoxin as determined by the QCL-1000 ${ }^{\mathrm{TM}}$ Endpoint chromogenic Limulus amoebocyte lysate assay. AOPPs-MSA was used at various concentrations as previously reported [10].

\section{Isolation of neonatal and adult mouse cardiomyocytes}

The investigation conformed to the Guide for the Care and Use of Laboratory Animals published by the US National Institutes of Health (NIH Publication No. 85-23, revised 1996) and was approved by the Institutional Animal Care and Use Committees of both Tulane University and University of Texas Health Science Center in San Antonio. Neonatal mouse cardiomyocytes (NMCM) were isolated as previously described [30, 31] from 1-3-day-old neonatal mice (wild type C57Bl/6 mice, The Jackson Laboratories). Cells were plated at a density of $1.0 \times 10^{5}$ cells $/ \mathrm{cm}^{2}$. Myocyte purity, determined by immunostaining for cardiacsarcomeric actin (Sigma-Aldrich), averaged $94 \pm 5 \% .24 \mathrm{~h}$ after plating, cardiomyocytes were treated with AOPPs-MSA.

To confirm whether AOPPs-MSA also induce adult cardiomyocte death, calcium-tolerant ventricular myocytes from 12 week-old male wild type C57Bl/6 and the TRAF3IP2-null (C57Bl/6 background) mice [28] were isolated as previously described [30]. The cells were plated on 35-mm cell culture dishes precoated with $20 \mu \mathrm{g} / \mathrm{ml}$ mouse laminin in phosphatebuffered saline with $1 \%$ penicillin-streptomycin for $1 \mathrm{~h}$. Cardiomyocytes were maintained under resting conditions in a humidified incubator for at least $4 \mathrm{~h}$ before experimentation.

\section{Adeno and lentiviral transduction}

Adenoviral GFP (Ad.GFP), Ad.dnJNK1, Ad.CuZnSOD, Ad.Bcl-2, and Ad.Bcl-xL have been previously described [32-34]. Ad.siNox2, Ad.siNox4, and Ad.siGFP were obtained from the University of Iowa Gene Vector Core after permission from Robin L. Davisson [35]. NMCM were infected at a multiplicity of infection (MOI) of 100 for $1 \mathrm{~h}$ at $22{ }^{\circ} \mathrm{C}$ in PBS. The infection medium was replaced with medium containing $0.5 \%$ BSA. After $24 \mathrm{~h}$ (Ad.GFP, Ad.dnJNK1, Ad.CuZnSOD, Ad.Bcl-2, and Ad.Bcl-xL) or 48 h (Ad.siNox2, Ad.siNox4, Ad.N17rac1, and Ad.siGFP), cells were treated with AOPPs-MSA. The transfection efficiency with adenoviral vectors was approximately $95 \%$ as determined by the 
expression of GFP in cardiomyocytes infected with Ad.GFP (data not shown). Lentiviral shRNA was used at MOI 0.5 for $48 \mathrm{~h}$. The knockdown of respective target proteins was confirmed by immunoblotting. The adeno or lentiviral vectors had no off-target effects, and failed to significantly modulate cardiomyocyte adherence, shape and viability (data not shown).

\section{Superoxide generation}

Superoxide $\left(\mathrm{O}_{2}^{-}\right)$generation was quantified using the lucigenin-enhanced chemiluminescence assay as previously described [33]. After subtracting background luminescence, results are expressed as RLU/second $/ 5 \times 10^{4}$ cells. Studies were also performed using NMCM infected with lentiviral RAGE shRNA or Ad.CuZnSOD or Ad.siNox2 (MOI 100 for $48 \mathrm{~h}$ ) prior to assay. Lentiviral GFP shRNA and Ad.siGFP served as respective controls.

\section{Electrophoretic mobility shift assay (EMSA)}

Quiescent NMCM were treated with polymyxin B $(10 \mu \mathrm{g} / \mathrm{ml}$ for $10 \mathrm{~min})$ prior to LPS (0.5 $\mu \mathrm{g} / \mathrm{ml}$ ) addition. After $2 \mathrm{~h}$, nuclear extracts were prepared using the Panomics Nuclear Extraction kit (\#AY2002, Panomics/Affymetrix, Freemont, CA) according to the manufacturer's instructions. Formation of NF- $\mathrm{kB}$ protein-DNA complexes was analyzed by EMSA as previously described [34] using nuclear protein extracts and NF- $\mathrm{KB}$-specific double-stranded consensus ( $5^{\prime}$-AGT TGA GGG GAC TTT CCC AGG C-3') and mutant ( $5^{\prime}$-AGT TGA GGC GAC TTT CCC AGG C-3') oligonucleotides (Santa Cruz Biotechnology, Inc.). Competition experiments (lanes 1 and 2) were performed with nuclear protein extracts from NMCM treated with LPS for $2 \mathrm{~h}$.

\section{Immunoblotting}

Extraction and preparation of whole cell lysates, mitochondria, nuclear and cytoplasmic extracts, electrophoresis, and immmunoblotting are all previously described [30, 32-34]. aTubulin (whole cell lysates), GAPDH (cytoplasmic), V- $\beta$ (mitochondrial) and Lamin A/C (nuclear) served as loading and purity controls. Caspase-3 activation was analyzed in AOPPs-MSA-treated $(8 \mathrm{~h})$ cardiomyocytes in parallel experiments.

\section{Rac1 and Caspase-3 activation assays}

Rac1 activity was assayed according to the manufacturer's protocol using an EZ-detect Rac1 activation kit (Pierce, Rockford, Ill), and has been previously described [34]. Caspase-3 activity was determined using a fluorescent Caspase-3 Activity Assay Kit. The assay is based on cleavage downstream of aspartate residues in the peptide sequence DEVD labeled with a fluorescent molecule, 7-amino-4-trifluoromethyl coumarin. Cardiomyocytes were homogenized in the provided lysis buffer, and centrifuged at $10,000 \mathrm{~g}$ for $20 \mathrm{~min}$ at $4^{\circ} \mathrm{C}$. The resulting supernatant was used for protein estimation and caspase- 3 activity assay. The cell lysates were treated with the substrate conjugate, and the resulting fluorescent intensity was measured in a fluorescent plate reader at excitation and emission wavelengths of 400 and $505 \mathrm{~nm}$, respectively. The data are expressed as a percent increase from the untreated control values.

\section{Cell Death}

To investigate whether the pharmacological inhibition, siRNA- or shRNA-mediated knockdown, and adenoviral transduction of dominant negative expression vectors modulate cell viability, we analyzed cell death using the Cell Death Detection ELISA ${ }^{\text {PLUS }}$ kit from Roche Applied Science. The assay is based on a quantitative sandwich-enzymeimmunoassay principle, using mouse monoclonal antibodies directed against DNA and 
histones, respectively. This allows the specific detection and quantitation of mono- and oligonucleosomes that are released into the cytoplasm of cells undergoing apoptosis [32]. All the components are provided in the kit. In brief, cytoplasmic fractions from treated and untreated controls were transferred onto a streptavidin-coated plate and incubated at $22^{\circ} \mathrm{C}$ for $2 \mathrm{~h}$ with a mixture of peroxidase conjugated anti-DNA and biotin-labeled anti-histone antibodies. The plate was washed, and then incubated with (2,2' -Azino-di[3-ethyl-benzthiazolin-sulfonat]) to photometrically detect nucleosomes. The absorbance was read at 405 $\mathrm{nm}$ with a reference wavelength at $490 \mathrm{~nm}$ (SPECTRAmax PLUS microplate reader). In addition, cell death was analyzed by DNA laddering using the Apoptotic DNA Ladder Kit (\#11 835246 001, Roche Applied Science, IN), and by the release of cytochrome $c$ from mitochondria into the cytoplasm [29]. Mitochondrial and cytoplasmic fractions were prepared using the Mitochondrial Fractionation Kit (Active Motif, Carlsbad, CA). Purity of extracts was analyzed by immunoblotting using cytoplasmic (GAPDH) and mitochondrial $(\mathrm{V}-\beta)$ markers. Cytochrome $c$ levels in cytoplasm were also analyzed colorimetrically using a commercially available kit (FunctionELISA ${ }^{\mathrm{TM}}$ Cytochrome $c$ kit, Active Motif).

\section{Statistical analysis}

Comparisons between controls and various treatments were performed by analysis of variance with post hoc Dunnett's $t$ tests. All assays were performed at least three times, and the error bars in the figures indicate the S.E. Densitometric results were shown as ratios and fold changes from untreated at the bottom of the panels whenever the results are less clear.

\section{Results \\ AOPPs induce cardiomyocyte death}

Coronary artery disease, atherosclerosis and chronic kidney failure are characterized by oxidative stress and enhanced systemic levels of advanced oxidation protein products [5-11], and AOPPs serve as independent risk factors for ischemic heart disease (IHD) [26]. IHD is characterized by cardiomyocyte injury and death. Here we investigated whether AOPPs affect survival of cultured cardiomyocytes. Concentrations of AOPPs-MSA thought to be pathological [10] induced death in primary neonatal mouse cardiomyocytes (NMCM) as evidenced by the increased levels of mono and oligonucleosomal fragmented DNA in cytoplasm (Fig. 1A). Cell death was induced in a dose-dependent manner, with concentrations as low as $10 \mu \mathrm{g} / \mathrm{ml}$ of AOPPs-MSA showing a significant effect, and a maximal response observed with $50 \mu \mathrm{g} / \mathrm{ml}$ AOPPs-MSA. Under similar conditions, unmodified MSA, even at $100 \mu \mathrm{g} / \mathrm{ml}$, failed to reduce NMCM viability (Fig. 1A). Therefore, in subsequent studies, both unmodified MSA and AOPPs-MSA were used at 50 $\mu \mathrm{g} / \mathrm{ml}$. The cell death effects of AOPPs-MSA were confirmed by DNA laddering (Fig. $1 B$ ), MTT assay (Fig. 1C), and caspase-3 activation (Fig. 1D; inset shows immunoblotting of the active form of caspase-3 [p17]). Further, while treatment with polymyxin B $(10 \mu \mathrm{g} / \mathrm{ml})$ alone failed to modify cell death (data not shown), its pre-treatment for $10 \mathrm{~min}$ prior to AOPPs-MSA addition also failed to modulate the pro-apoptotic effects of AOPPs-MSA as evidenced by similar levels of mono and oligonucleosomal fragmented DNA (Fig. $1 E$ ) and active caspase-3 levels (Fig. $1 E$, inset). However, polymyxin B inhibited LPS-induced NF$\mathrm{\kappa B}$ activation (Fig. 1F). These results demonstrate that the AOPPs-MSA-induced cardiomyocyte death was not mediated by the very low levels of endotoxin present in the AOPPs-MSA preparations. Together, these results indicate that AOPPs exert potent proapoptotic effects on cardiomyocytes (Fig. 1).

\section{AOPPs-induced cardiomyocyte death is RAGE and TRAF3IP2 dependent}

Since AOPPs have been shown to signal via RAGE and CD36 [10-12], and as cardiomyocytes are known to express both receptors, we next investigated their role in 
NMCM death. Knockdown of RAGE with shRNA, or pre-treatment with anti-RAGE neutralizing antibodies prior to AOPPs-MSA addition, markedly attenuated AOPPs-MSA induced NMCM death (Fig. $2 A$; knockdown and specificity was confirmed by immunoblotting and is shown on the right). However, knockdown of CD36 or incubation with anti-CD36 neutralizing antibodies failed to have an effect (Fig. 2A). Knockdown of TRAF3IP2, on the other hand, blunted AOPPs-MSA induced NMCM death (Fig. $2 A$ ). We next investigated whether AOPPs-MSA exerts similar effects in adult cardiomyocytes. Indeed, confirming our results in neonatal cardiomyocytes (Fig. 1), AOPPs-MSA induced significant death of adult wild type (WT) cardiomyocytes, and TRAF3IP2 gene deletion blunted this effect, despite similar basal levels of RAGE (Fig. 2B; RAGE levels were analyzed by immunoblotting and are shown in the inset). Similar results were obtained in adult WT cardiomyocytes infected with lentiviral TRAF3IP2 shRNA (data not shown). Results obtained by cell death ELISA were confirmed by immunoblotting for caspase-3 activation (Fig. 2B, lower panel). These results indicate that AOPPs induce cardiomyocyte death via RAGE and TRAF3IP2 (Fig. 2).

\section{AOPPs-MSA induces TRAF3IP2 expression in NMCM mainly via Nox2, Rac1 and ROS}

Previously, we demonstrated that Ang-II induced TRAF3IP2 expression in cardiomyocytes via a mechanism involving ROS generation, the NADPH oxidase Nox2, and the Rho family protein Rac1 [30]. Since AOPPs induced cardiomyocyte death via RAGE and TRAF3IP2 (Figs. 1 and 2), and RAGE signaling is associated with Nox-dependent ROS generation [33], we next investigated whether AOPPs also induce TRAF3IP2 expression. In a lucigenin-enhanced chemiluminescence assay, AOPPs-MSA stimulated significant ROS generation in NMCM, an effect markedly attenuated by RAGE knockdown (Fig. $3 A$ ), and by the flavoprotein inhibitor DPI and the superoxide scavenger Tiron (Fig. $3 A$ ). Since cardiomyocytes are known to express both Nox 2 and Nox4, we targeted their expression by adenoviral siRNA, and quantified AOPPs-MSA-induced ROS generation. While infection with Ad.siNox 2 knocked down Nox 2 expression, it had no effect on Nox4 levels. Similarly, infection with Ad.siNox4 knocked down Nox4, but not Nox2, demonstrating no off-target effects (Fig. $3 A$, right hand panels). Our results show that knockdown of Nox 2 and Nox4 each resulted in attenuated ROS generation. Although the difference between Nox 2 and Nox4 did not achieve statistical significance, the inhibitory effects appeared to be somewhat greater following Nox 2 knockdown (Fig. $3 A$ ). Therefore, subsequent studies were focused on this Nox isoform. Since Rac1, a member of the Rho family of GTPases, is critical for the activation of the Nox2 NADPH oxidase complex [36], we next investigated its role in AOPPs-MSA signaling. Forced expression of dominant negative Rac1 (N17rac1) in NMCM inhibited both AOPPs-MSA-induced superoxide production (Fig. $3 A$; Myc expression from N17rac1 was analyzed by immunoblotting and is shown on the right), and induction of activated Rac1 (Fig, 3B). Further, confirming our earlier results in human coronary artery endothelial cells [28], AOPPs-MSA induced time-dependent TRAF3IP2 protein expression in NMCM (Fig. 3C), and knockdown of RAGE or Nox2, overexpression of N17rac1, or treatment with DPI or Tiron each blunted this effect (Fig. 3D). Further, DPI pre-treatment or Nox2 knockdown blunted AOPPs-MSA-induced NMCM death (Fig. 3E). Caspase-3 activation confirmed these results (Fig. 3E, inset). Thus, although a role for Nox4 cannot be excluded, AOPPs-MSA induces TRAF3IP2 expression via Nox2/Rac1-dependent superoxide generation (Fig. 3).

\section{ROS induce TRAF3IP2 expression in NMCM}

The major species of ROS generated by Nox 2 activation is superoxide. Superoxide is then converted to hydrogen peroxide by superoxide dismutase, and subsequently to oxygen and water by catalase. Since DPI and Nox2 knockdown each blunted AOPPs-MSA-induced TRAF3IP2 expression (Fig. 3D), we next investigated whether superoxide and hydrogen 
peroxide can directly induce TRAF3IP2 expression in NMCM. Superoxide was generated by the addition of xanthine (X) and xanthine oxidase (XO) [37]. Since $\mathrm{X} / \mathrm{XO}$ also produces hydrogen peroxide[38], we incubated NMCM with $\mathrm{X} / \mathrm{XO}$ in the presence of catalase to decompose hydrogen peroxide. In the presence of a fixed concentration of $X(0.1 \mathrm{mM})$ and increasing concentrations of XO, TRAF3IP2 expression was induced in the NMCM (Fig. $4 A$ ), and this effect was time-dependent (Fig. 4B). Further, induction of TRAF3IP2 was markedly attenuated by the forced expression of CuZnSOD in these cells (Fig. 4C). Similar to $\mathrm{X} / \mathrm{XO}$, hydrogen peroxide also induced TRAF3IP2 expression in a dose- (Fig. $4 D$ ) and time- (Fig. $4 E$ ) dependent manner, and simultaneous addition of catalase or infection with Ad.catalase markedly attenuated this effect (Fig. 4F>), as did overexpression of CuZnSOD by adenoviral transduction (Fig. $4 G$ ). These results indicate that both radical and non-radical ROS induce TRAF3IP2 expression in cardiomyocytes (Fig. 4).

\section{AOPPs-MSA induces NMCM death via JNK}

We have demonstrated that AOPPs-MSA-induced cardiomyocyte death is markedly attenuated by TRAF3IP2 knockdown (Fig. 2). We have previously reported that TRAF3IP2, via IKK $\gamma$, activates JNK in cardiomyocytes [30], and since JNK has been implicated in the cell death pathways, we next investigated whether AOPPs-MSA induces cardiomyocyte death via JNK. Initially, we determined whether AOPPs-MSA induces JNK activation. JNK activation was analyzed by immunoblotting using activation-specific antibodies. AOPPsMSA induced JNK phosphorylation in a time-dependent manner, and this effect could be inhibited by the JNK inhibitor SP600125, forced expression of mutant JNK1 by adenoviral transduction (Fig. $5 A$ ), or by TRAF3IP2 knockdown (Fig. 5B). Further, AOPPs-MSA induced time-dependent c-Jun phosphorylation (Fig. $5 C$ ) and nuclear translocation (Fig. $5 D$ ), and pre-treatment with SP600125 (Fig. 5E) or TRAF3IP2 knockdown (Fig. 5F) blunted c-Jun transactivation. Notably, targeting JNK by SP600125 or forced expression of mutant JNK1 inhibited AOPPs-MSA induced caspase-3 activation (inset) and cardiomyocyte death (Fig. $5 G$ ), indicating that AOPPs-MSA induces cardiomyocyte death via TRAF3IP2/JNKdependent c-Jun activation (Fig. 5).

\section{AOPPs-MSA activates pro-apoptotic signaling in NMCM via JNK}

Bax, the pro-apoptotic Bcl-2 family member, is sequestered in the cytoplasm bound to 14-3-3 proteins [39]. Under stress conditions, it dissociates from these proteins, translocates to mitochondria, induces pore formation in the outer mitochondrial membrane, and promotes cytochrome $c$ release into cytoplasm [40]. Since targeting JNK blunted AOPPs-MSA induced cardiomyocyte death, we next investigated whether AOPPs-MSA induces Bax translocation to mitochondria in a JNK-dependent manner. Addition of AOPPs-MSA reduced cytoplasmic Bax levels in a time dependent manner, while simultaneously increasing its levels in mitochondrial fraction (Fig. 6A). Inhibition of JNK with SP600125 reversed this response (Fig. $6 B$ ), and further, inhibited cytochrome $c$ release into the cytoplasm (Fig. $6 C$ ). AOPPs-MSA also induced a marked activation of the pro-apoptotic caspase-3, an effect blunted by both pan-caspase and caspase-3 inhibitors (Fig. $6 D$ ). Notably, the caspase- 3 inhibitor inhibited AOPPs-MSA induced caspase-3 activation (inset) and cardiomyocyte death (Fig. $6 E$ ). These results indicate that AOPPs-MSA activates the mitochondrial cells death signaling in NMCM via JNK (Fig. 6).

\section{AOPPs-MSA inhibits anti-apoptotic Bcl-2 and Bcl-xL expression}

The Bcl-2 family contains both pro- (e.g., Bax) and anti- (e.g., Bcl-2 and Bcl-xL) apoptotic members. Since AOPPs-MSA induces mitochondrial translocation of Bax, cytochrome $c$ release (Fig. 6), and death (Fig. 1), we next investigated whether forced expression of antiapoptotic Bcl-2 or Bcl-xL reverses AOPPs-MSA-induced cardiomyocyte death. AOPPsMSA inhibited Bcl-2 expression in the NMCM, an effect reversed by either SP600125 (Fig. 
$7 A$ ), or forced expression of dnJNK1 by adenoviral transduction (Fig. 7B). Similarly, AOPPs-MSA inhibited Bcl-xL expression, an effect also reversed by JNK inhibition or dnJNK1 overexpression (Fig. 7C). Notably, forced expression of Bcl-2 or Bcl-xL blunted AOPPs-MSA induced caspase-3 activation (inset) and NMCM death (Fig. 7D; increased expression of Bcl-2 and Bcl-xL was confirmed by immunoblotting, and is shown on the right), indicating that AOPPs-MSA induce cardiomyocyte death by tilting the delicate balance between pro- and anti-apoptotic Bcl-2 family members towards activation of JNKdependent pro-death signaling (Fig. 7).

\section{Discussion}

Systemic levels of advanced oxidation protein products (AOPPs) are increased in the circulation in diabetes mellitus, atherosclerosis, coronary artery disease and chronic kidney disease [5-11]. Further, in patients undergoing renal dialysis, there is a positive correlation between systemic AOPPs and ischemic heart disease [26]. Since ischemic heart disease (IHD) is characterized by cardiomyocyte death, we investigated whether AOPPs affect cardiomyocyte survival. Our results show that AOPPs induce death of neonatal mouse cardiomyocytes (NMCM), and this effect is mediated via RAGE, and not CD36. AOPPs induced Nox2- and Nox4-dependent superoxide generation, increased TRAF3IP2 expression, TRAF3IP2-dependent JNK activation, c-Jun transactivation, Bax translocation to mitochondria, cytochrome $c$ release, and caspase- 3 activation. Further, AOPPs inhibited Bcl-2 and Bcl-xL expression, and forced expression of Bcl-2 or Bcl-xL blocked NMCM death. Knockdown of the adapter protein TRAF3IP2 blunted AOPPs-induced cell death in both NMCM and adult cardiomyocytes. These results demonstrate that AOPPs shifts the cellular balance between pro-apoptotic and anti-apoptotic Bcl-2 family proteins towards cell death, and TRAF3IP2 is a critical intermediate in this signaling. These results suggest that enhanced systemic AOPPs levels observed during various chronic oxidative stress conditions exert deleterious effects on cardiomyocytes via TRAF3IP2. Thus TRAF3IP2 may represent a potential therapeutic target in IHD.

Knockdown of RAGE, or incubation with anti-RAGE neutralizing antibodies, blocked AOPPs-induced ROS generation and TRAF3IP2 expression. Knockdown of Nox2 or Nox4, overexpression of mutant Rac1 (N17rac1), treatment with the flavoprotein inhibitor DPI, forced expression CuZnSOD, or the superoxide scavenger Tiron, each inhibited AOPPsinduced superoxide generation and TRAF3IP2 induction, indicating that TRAF3IP2 is a redox-sensitive signaling intermediate. In fact, just the generation of superoxide alone, by adding an extracellular superoxide generating enzyme system (xanthine/xanthine oxidase) was sufficient to induce the rapid expression of TRAF3IP2 in cardiomyocytes. Addition of hydrogen peroxide also induced TRAF3IP2 expression in NMCM in a dose and timedependent manner. Thus AOPPs, formed as a result of oxidative stress, induce ROS generation via NADPH oxidase, and can perpetuate oxidative stress conditions. Of note, $R A G E$ is also an oxidative stress-responsive gene. The $R A G E$ gene promoter contains several transcription factor-binding sites, including NF- $\mathrm{kB}, \mathrm{AP}-1$ and Sp1 that are ROS sensitive [41]. Interestingly, RAGE expression is increased in the ischemic heart, and $R A G E$ gene deletion or targeting its expression blunted cardiac injury [42, 43].

Our study also shows that AOPPs induce JNK phosphorylation and c-Jun activation through a RAGE/ROS/TRAF3IP2 pathway. Although TRAF3IP2 is instrumental in activating both NF- $\kappa$ B and AP-1 [21, 22], and since AOPPs inhibit proliferation of rat osteoblast-like cells in part via NF- $\kappa B$ [13], we investigated whether NF- $\mathrm{BB}$ might modulate AOPPs-induced cardiomyocyte death. Neither p65 knockdown nor its overexpression significantly modulated AOPPs-induced death in NMCM (data not shown), indicating that TRAF3IP2dependent JNK activation is the major step in AOPPs-induced cardiomyocyte death. In fact, 
the JNK specific inhibitor SP600125 or forced expression of dnJNK1 each was effective in blunting AOPPs-induced cardiomyocyte death.

Recently, AOPPs have been shown to induce various components of the RAS system (angiotensinogen, ACE, angiotensin (Ang)-II type I receptor [AT1] expression, ACE activation, and Ang-II secretion) in proximal tubular epithelial cells [12]. Using either pharmacological inhibitors or gene knockdown, the authors further demonstrated the activation of NF- $\mathrm{kB}$ and AP-1 in these cells via CD36/PKCa/Nox/ROS signaling. Since chronic activation of the RAS contributes to cardiovascular pathology, it is possible that AOPPs might also induce components of the RAS in cardiomyocytes. Recently, we demonstrated that Ang-II induces TRAF3IP2 expression, and activates both IKK/NF- $\kappa B$ and JNK/AP-1 in cardiomyocytes [30]. In that study, we also demonstrated that TRAF3IP2 physically associates with IKK $\gamma$, activates NF- $\mathrm{KB}$ and JNK, and mediates cardiomyocyte hypertrophy [30]. Here we demonstrate that AOPPs activate JNK, and induce cardiomyocyte death. Since both AOPPs and Ang-II induce oxidative stress in cardiomyocytes, signal via TRAF3IP2, and exert differential effects, in future studies it will be critical to determine whether AOPPs modulate Ang-II effects on cardiomyocytes.

The Bcl-2 family of proteins, consisting of both pro- (e.g., Bax, Bad, Bim) and antiapoptotic (e.g., Bcl-2, Bcl-xL) members, is a critical determinant of cell survival and death. Here we show that AOPPs induce Bax translocation to mitochondria, increase cytochrome $c$ release, and activate caspase-3, all in JNK-dependent manner. Further, AOPPs inhibited the anti-apoptotic Bcl-2 and Bcl-xL expression, and importantly, forced expression of dnJNK1 or JNK inhibition restored Bcl-2 or Bcl-xL expression, and reversed AOPPs-induced cardiomyocyte death. These data indicate that AOPPs shift the regulatory balance of the Bcl-2 family proteins in favor of cell death by promoting TRAF3IP2/JNK-dependent Bax activation.

Cardiomyocyte death contributes to progression of various cardiovascular diseases, including IHD. Systemic levels of AOPPs are increased in diverse chronic oxidative conditions, including diabetes mellitus, chronic kidney and coronary artery disease [5-11]. In addition, administration of AOPPs to hypercholesterolemic rabbits accelerated atherosclerotic lesion development and enhanced markers of systemic oxidative stress and inflammation [44]. Further, subjects with acute myocardial infarction and unstable angina display higher AOPP/Thiol ratio, and a positive correlation with systemic CRP and IL-1 $\beta$ compared to control subjects [45]. Like AOPPs, systemic levels of oxidized LDL (oxLDL) are also increased in atherosclerosis and cardiovascular diseases. Like AOPPs, oxLDL induces cardiomyocyte damage [46]. Further, a positive correlation between CRP and oxLDL has been described in acute coronary syndromes and coronary artery disease [47]. While CRP and oxLDL when used alone exert potent pro-atherogenic and pro-oxidant effects, the CRP-oxLDL complexes are markedly less active [48]. This suggests that CRP binds and sequesters oxLDL. Recently, CRP has been shown to bind both oxLDL and cells undergoing apoptosis through recognition of phosphorylcholine of oxidized phosphatidylcholine [48, 49]. It is possible that any phosphatidylcholine bound to MSA will also become oxidized by exposure to the $\mathrm{HOCl}$, and provides a possible target for CRP binding. This might result in the sequestration of the AOPPs and a mechanism for their removal. Currently, we do not have data to support the hypothesis that CRP binds AOPPs directly. However, in our future studies, we will determine whether CRP interacts with AOPPs in vivo and whether their interaction attenuates AOPPs-induced cardiomyocyte death in vitro. Nevertheless, our data suggest that increased systemic AOPPs may contribute to initiation and progression of IHD. Since cardiovascular diseases are the major contributors of morbidity and mortality, it is possible that increased AOPPs-mediated TRAF3IP2-dependent cardiomyocyte death might perpetuate myocardial injury and increase 
mortality. Since AOPPs serve as independent risk factors for IHD, and as TRAF3IP2 knockdown or gene deletion blunts AOPPs-induced cardiomyocyte death, our results suggest that TRAF3IP2 may represent a potential therapeutic target in ischemic heart disease.

\section{Acknowledgments}

BC is a recipient of the Department of Veterans Affairs Research Career Scientist award, and is supported by VA Office of Research and Development Biomedical Laboratory Research and Development Service Award 1IO1BX000246 and the NIH/NHLBI grant HL-86787. The contents of this report do not represent the views of the Department of Veterans Affairs or the United States Government. P. Delafontaine is supported by NHLBI grants HL-70241 and HL-80682.

\section{Abbreviations used in this paper}

$\begin{array}{ll}\text { Act1 } & \text { activator of NF- } \text { B } \\ \text { AGE } & \text { advanced glycation end products } \\ \text { AOPPs } & \text { advanced oxidation protein products } \\ \text { AP-1 } & \text { activator protein-1 } \\ \text { CD36 } & \text { cluster determinant 36 } \\ \text { CIKS } & \text { Connection to IKK and SAPK/JNK } \\ \text { dn, CRP } & \text { C-reactive protein; dominant negative } \\ \text { CuZnSOD } & \text { copper/zinc superoxide dismutase } \\ \text { DPI } & \text { diphenylene iodonium } \\ \text { GFP } & \text { green fluorescent protein } \\ \text { gp91phox } & \text { 91-kDa glycoprotein component of the phagocyte NADPH oxidase } \\ \text { HOCl } & \text { hypochlorous acid } \\ \text { IxB } & \text { inhibitory } \text { kB } \\ \text { IKK } & \text { IxB kinase } \\ \text { JNK } & \text { c-Jun amino-terminal kinase } \\ \text { kd } & \text { kinase deficient } \\ \text { LPS } & \text { Lipopolysaccharide } \\ \text { MOI } & \text { multiplicity of infection } \\ \text { MSA } & \text { mouse serum albumin } \\ \text { MTT } & \text { 3-(4,5-dimethylthiazol-2-yl)-2,5-diphenyltetrazolium bromide } \\ \text { NF- } \text { KB } & \text { nuclear factor kappa B } \\ \text { NMCM } & \text { neonatal mouse cardiomyocytes } \\ \text { Nox } & \text { NADPH oxidase } \\ \text { NADPH } & \text { nicotinamide adenine dinucleotide phosphate } \\ \text { oxLDL } & \text { oxidized low density lipoprotein } \\ \text { PKCa } & \text { Protein kinase C alpha } \\ \text { RAGE } & \text { receptor for AGEs } \\ & \end{array}$




$\begin{array}{ll}\text { ROS } & \text { reactive oxygen species } \\ \text { SAPK } & \text { stress-activated protein kinase } \\ \text { siRNA } & \text { small interfering RNA } \\ \text { shRNA } & \text { small hairpin RNA } \\ \text { TRAF } & \text { TNF Receptor Associated Factor } \\ \text { TRAF3IP2 } & \text { TRAF3 interacting protein 2 } \\ \text { TNF } & \text { tumor necrosis factor } \\ \text { UTR } & \text { untranslated region } \\ \text { WT } & \text { wild-type }\end{array}$

\section{References cited}

[1]. Sabri A, Hughie HH, Lucchesi PA. Regulation of hypertrophic and apoptotic signaling pathways by reactive oxygen species in cardiac myocytes. Antioxid Redox Signal. 2003; 5:731-740. [PubMed: 14588146]

[2]. Bedard K, Krause KH. The NOX family of ROS-generating NADPH oxidases: physiology and pathophysiology. Physiol Rev. 2007; 87:245-313. [PubMed: 17237347]

[3]. Maejima Y, Kuroda J, Matsushima S, Ago T, Sadoshima J. Regulation of myocardial growth and death by NADPH oxidase. J Mol Cell Cardiol. 2011; 50:408-416. [PubMed: 21215757]

[4]. Looi YH, Grieve DJ, Siva A, Walker SJ, Anilkumar N, Cave AC, Marber M, Monaghan MJ, Shah AM. Involvement of Nox2 NADPH oxidase in adverse cardiac remodeling after myocardial infarction. Hypertension. 2008; 51:319-325. [PubMed: 18180403]

[5]. Sorescu D, Weiss D, Lassegue B, Clempus RE, Szocs K, Sorescu GP, Valppu L, Quinn MT, Lambeth JD, Vega JD, Taylor WR, Griendling KK. Superoxide production and expression of nox family proteins in human atherosclerosis. Circulation. 2002; 105:1429-1435. [PubMed: 11914250]

[6]. Brownlee M. Biochemistry and molecular cell biology of diabetic complications. Nature. 2001; 414:813-820. [PubMed: 11742414]

[7]. Kaneda H, Taguchi J, Ogasawara K, Aizawa T, Ohno M. Increased level of advanced oxidation protein products in patients with coronary artery disease. Atherosclerosis. 2002; 162:221-225. [PubMed: 11947918]

[8]. Kalousova M, Skrha J, Zima T. Advanced glycation end-products and advanced oxidation protein products in patients with diabetes mellitus. Physiol Res. 2002; 51:597-604. [PubMed: 12511184]

[9]. Witko-Sarsat V, Friedlander M, Capeillere-Blandin C, Nguyen-Khoa T, Nguyen AT, Zingraff J, Jungers P, Descamps-Latscha B. Advanced oxidation protein products as a novel marker of oxidative stress in uremia. Kidney Int. 1996; 49:1304-1313. [PubMed: 8731095]

[10]. Guo ZJ, Niu HX, Hou FF, Zhang L, Fu N, Nagai R, Lu X, Chen BH, Shan YX, Tian JW, Nagaraj $\mathrm{RH}$, Xie D, Zhang X. Advanced oxidation protein products activate vascular endothelial cells via a RAGE-mediated signaling pathway. Antioxid Redox Signal. 2008; 10:1699-1712. [PubMed: 18576917]

[11]. Zhou LL, Cao W, Xie C, Tian J, Zhou Z, Zhou Q, Zhu P, Li A, Liu Y, Miyata T, Hou FF, Nie J. The receptor of advanced glycation end products plays a central role in advanced oxidation protein products-induced podocyte apoptosis. Kidney Int. 2012; 82:759-770. [PubMed: 22622498]

[12]. Cao W, Xu J, Zhou ZM, Wang GB, Hou FF, Nie J. Advanced Oxidation Protein Products Activate Intrarenal Renin-Angiotensin System via a CD36-Mediated, Redox-Dependent Pathway. Antioxid Redox Signal. 2012 
[13]. Zhong ZM, Bai L, Chen JT. Advanced oxidation protein products inhibit proliferation and differentiation of rat osteoblast-like cells via NF-kappaB pathway. Cell Physiol Biochem. 2009; 24:105-114. [PubMed: 19590198]

[14]. Wei XF, Zhou QG, Hou FF, Liu BY, Liang M. Advanced oxidation protein products induce mesangial cell perturbation through PKC-dependent activation of NADPH oxidase. Am J Physiol Renal Physiol. 2009; 296:F427-437. [PubMed: 19019916]

[15]. Zhou QG, Zhou M, Lou AJ, Xie D, Hou FF. Advanced oxidation protein products induce inflammatory response and insulin resistance in cultured adipocytes via induction of endoplasmic reticulum stress. Cell Physiol Biochem. 2010; 26:775-786. [PubMed: 21063115]

[16]. Hilenski LL, Clempus RE, Quinn MT, Lambeth JD, Griendling KK. Distinct subcellular localizations of Noxl and Nox4 in vascular smooth muscle cells. Arterioscler Thromb Vasc Biol. 2004; 24:677-683. [PubMed: 14670934]

[17]. Mustapha S, Kirshner A, De Moissac D, Kirshenbaum LA. A direct requirement of nuclear factor-kappa B for suppression of apoptosis in ventricular myocytes. Am J Physiol Heart Circ Physiol. 2000; 279:H939-945. [PubMed: 10993753]

[18]. Maulik N, Sasaki H, Addya S, Das DK. Regulation of cardiomyocyte apoptosis by redoxsensitive transcription factors. FEBS Lett. 2000; 485:7-12. [PubMed: 11086156]

[19]. Gordon JW, Shaw JA, Kirshenbaum LA. Multiple facets of NF-kappaB in the heart: to be or not to NF-kappaB. Circ Res. 2011; 108:1122-1132. [PubMed: 21527742]

[20]. Bogoyevitch MA, Kobe B. Uses for JNK: the many and varied substrates of the c-Jun N-terminal kinases. Microbiol Mol Biol Rev. 2006; 70:1061-1095. [PubMed: 17158707]

[21]. Leonardi A, Chariot A, Claudio E, Cunningham K, Siebenlist U. CIKS, a connection to Ikappa B kinase and stress-activated protein kinase. Proc Natl Acad Sci USA. 2000; 97:10494-10499. [PubMed: 10962033]

[22]. Li X, Commane M, Nie H, Hua X, Chatterjee-Kishore M, Wald D, Haag M, Stark GR. Act1, an NF-kappa B-activating protein. Proc Natl Acad Sci USA. 2000; 97:10489-10493. [PubMed: 10962024]

[23]. Liu C, Qian W, Qian Y, Giltiay NV, Lu Y, Swaidani S, Misra S, Deng L, Chen ZJ, Li X. Act1, a U-box E3 ubiquitin ligase for IL-17 signaling. Sci Signal. 2009; 2:ra63. [PubMed: 19825828]

[24]. Chang SH, Dong C. Signaling of interleukin-17 family cytokines in immunity and inflammation. Cell Signal. 2011; 23:1069-1075. [PubMed: 21130872]

[25]. Liao YH, Xia N, Zhou SF, Tang TT, Yan XX, Lv BJ, Nie SF, Wang J, Iwakura Y, Xiao H, Yuan J, Jevallee H, Wei F, Shi GP, Cheng X. Interleukin-17A contributes to myocardial ischemia/ reperfusion injury by regulating cardiomyocyte apoptosis and neutrophil infiltration. J Am Coll Cardiol. 2012; 59:420-429. [PubMed: 22261166]

[26]. Zhou Q, Wu S, Jiang J, Tian J, Chen J, Yu X, Chen P, Mei C, Xiong F, Shi W, Zhou W, Liu X, Sun S, Xie D, Liu J, Xu X, Liang M, Hou F. Accumulation of circulating advanced oxidation protein products is an independent risk factor for ischaemic heart disease in maintenance haemodialysis patients. Nephrology (Carlton). 2012; 17:642-649. [PubMed: 22738256]

[27]. Witko-Sarsat V, Gausson V, Nguyen AT, Touam M, Drueke T, Santangelo F, Descamps-Latscha B. AOPP-induced activation of human neutrophil and monocyte oxidative metabolism: a potential target for N-acetylcysteine treatment in dialysis patients. Kidney Int. 2003; 64:82-91. [PubMed: 12787398]

[28]. Venkatesan B, Valente AJ, Das NA, Carpenter AJ, Yoshida T, Delafontaine JL, Siebenlist U, Chandrasekar B. CIKS (Act1 or TRAF3IP2) mediates high glucose-induced endothelial dysfunction. Cell Signal. 2012

[29]. Capeillere-Blandin C, Gausson V, Descamps-Latscha B, Witko-Sarsat V. Biochemical and spectrophotometric significance of advanced oxidized protein products. Biochim Biophys Acta. 2004; 1689:91-102. [PubMed: 15196590]

[30]. Valente AJ, Clark RA, Siddesha JM, Siebenlist U, Chandrasekar B. CIKS (Act1 or TRAF3IP2) mediates Angiotensin-II-induced Interleukin-18 expression, and Nox2-dependent cardiomyocyte hypertrophy. J Mol Cell Cardiol. 2012; 53:113-124. [PubMed: 22575763] 
[31]. Golden HB, Gollapudi D, Gerilechaogetu F, Li J, Cristales RJ, Peng X, Dostal DE. Isolation of cardiac myocytes and fibroblasts from neonatal rat pups. Methods Mol Biol. 2012; 843:205-214. [PubMed: 22222535]

[32]. Venkatesan B, Prabhu SD, Venkatachalam K, Mummidi S, Valente AJ, Clark RA, Delafontaine P. Chandrasekar, B. WNT1-inducible signaling pathway protein-1 activates diverse cell survival pathways and blocks doxorubicin-induced cardiomyocyte death. Cell Signal. 2010; 22:809-820. [PubMed: 20074638]

[33]. Shanmugam P, Valente AJ, Prabhu SD, Venkatesan B, Yoshida T, Delafontaine P, Chandrasekar B. Angiotensin-II type 1 receptor and NOX2 mediate TCF/LEF and CREB dependent WISP1 induction and cardiomyocyte hypertrophy. J Mol Cell Cardiol. 2011; 50:928938.

[34]. Venkatesan B, Valente AJ, Prabhu SD, Shanmugam P, Delafontaine P, Chandrasekar B. EMMPRIN activates multiple transcription factors in cardiomyocytes, and induces interleukin-18 expression via Rac1-dependent PI3K/Akt/IKK/NF-kappaB andMKK7/JNK/AP-1 signaling. J Mol Cell Cardiol. 2010; 49:655-663. [PubMed: 20538003]

[35]. Peterson JR, Burmeister MA, Tian X, Zhou Y, Guruju MR, Stupinski JA, Sharma RV, Davisson RL. Genetic silencing of Nox 2 and Nox4 reveals differential roles of these NADPH oxidase homologues in the vasopressor and dipsogenic effects of brain angiotensin II. Hypertension. 2009; 54:1106-1114. [PubMed: 19805637]

[36]. Hordijk PL. Regulation of NADPH oxidases: the role of Rac proteins. Circ Res. 2006; 98:453462. [PubMed: 16514078]

[37]. Li PF, Dietz R, von Harsdorf R. Superoxide induces apoptosis in cardiomyocytes, but proliferation and expression of transforming growth factor-beta1 in cardiac fibroblasts. FEBS Lett. 1999; 448:206-210. [PubMed: 10218477]

[38]. Sato E, Mokudai T, Niwano Y, Kohno M. Kinetic analysis of reactive oxygen species generated by the in vitro reconstituted NADPH oxidase and xanthine oxidase systems. J Biochem. 2011; 150:173-181. [PubMed: 21572100]

[39]. Nomura M, Shimizu S, Sugiyama T, Narita M, Ito T, Matsuda H, Tsujimoto Y. 14-3-3 Interacts directly with and negatively regulates pro-apoptotic Bax. J Biol Chem. 2003; 278:2058-2065. [PubMed: 12426317]

[40]. Tsuruta F, Sunayama J, Mori Y, Hattori S, Shimizu S, Tsujimoto Y, Yoshioka K, Masuyama N, Gotoh Y. JNK promotes Bax translocation to mitochondria through phosphorylation of 14-3-3 proteins. EMBO J. 2004; 23:1889-1899. [PubMed: 15071501]

[41]. Li J, Qu X, Schmidt AM. Sp1-binding elements in the promoter of RAGE are essential for amphoterin-mediated gene expression in cultured neuroblastoma cells. J Biol Chem. 1998; 273:30870-30878. [PubMed: 9812979]

[42]. Bucciarelli LG, Kaneko M, Ananthakrishnan R, Harja E, Lee LK, Hwang YC, Lerner S, Bakr S, Li Q, Lu Y, Song F, Qu W, Gomez T, Zou YS, Yan SF, Schmidt AM, Ramasamy R. Receptor for advanced-glycation end products: key modulator of myocardial ischemic injury. Circulation. 2006; 113:1226-1234. [PubMed: 16505177]

[43]. Aleshin A, Ananthakrishnan R, Li Q, Rosario R, Lu Y, Qu W, Song F, Bakr S, Szabolcs M, D'Agati V, Liu R, Homma S, Schmidt AM, Yan SF, Ramasamy R. RAGE modulates myocardial injury consequent to LAD infarction via impact on JNK and STAT signaling in a murine model. Am J Physiol Heart Circ Physiol. 2008; 294:H1823-1832. [PubMed: 18245563]

[44]. Liu SX, Hou FF, Guo ZJ, Nagai R, Zhang WR, Liu ZQ, Zhou ZM, Zhou M, Xie D, Wang GB, Zhang X. Advanced oxidation protein products accelerate atherosclerosis through promoting oxidative stress and inflammation. Arterioscler Thromb Vasc Biol. 2006; 26:1156-1162. [PubMed: 16497990]

[45]. Barsotti A, Fabbi P, Fedele M, Garibaldi S, Balbi M, Bezante GP, Risso D, Indiveri F, Ghigliotti $\mathrm{G}$, Brunelli C. Role of advanced oxidation protein products and Thiol ratio in patients with acute coronary syndromes. Clin Biochem. 44:605-611. [PubMed: 21458436]

[46]. Zorn-Pauly K, Schaffer P, Pelzmann B, Bernhart E, Wei G, Lang P, Ledinski G, Greilberger J, Koidl B, Jurgens G. Oxidized LDL induces ventricular myocyte damage and abnormal electrical activity--role of lipid hydroperoxides. Cardiovasc Res. 2005; 66:74-83. [PubMed: 15769450] 
[47]. Holvoet P, Vanhaecke J, Janssens S, Van de Werf F, Collen D. Oxidized LDL and malondialdehyde-modified LDL in patients with acute coronary syndromes and stable coronary artery disease. Circulation. 1998; 98:1487-1494. [PubMed: 9769301]

[48]. Chang MK, Binder CJ, Torzewski M, Witztum JL. C-reactive protein binds to both oxidized LDL and apoptotic cells through recognition of a common ligand: Phosphorylcholine of oxidized phospholipids. Proc Natl Acad Sci USA. 2002; 99:13043-13048. [PubMed: 12244213]

[49]. Chang MK, Hartvigsen K, Ryu J, Kim Y, Han KH. The pro-atherogenic effects of macrophages are reduced upon formation of a complex between $\mathrm{C}$-reactive protein and lysophosphatidylcholine. J Inflamm (Lond). 2012; 9:42. [PubMed: 23114023] 


\section{Highlights}

Advanced oxidation protein products induce cardiomyocyte death AOPPs induce Nox2/Rac1/ROS-dependent TRAF3IP2 expression Superoxide and hydrogen peroxide induce TRAF3IP2 expression AOPPs activate TRAF3IP2/JNK-dependent pro-apoptotic signaling TRAF3IP2 may represent a potential therapeutic target. 
A
B

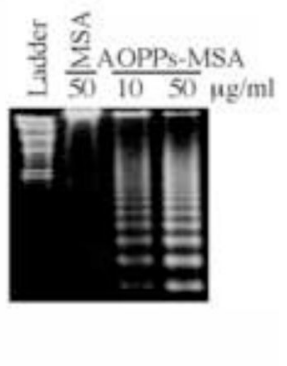

C

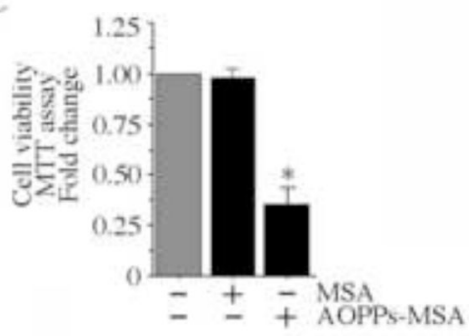

D

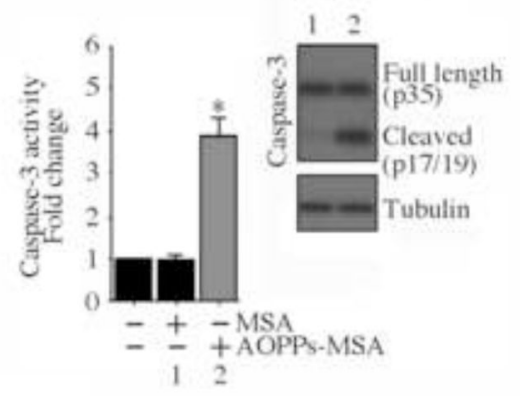

E

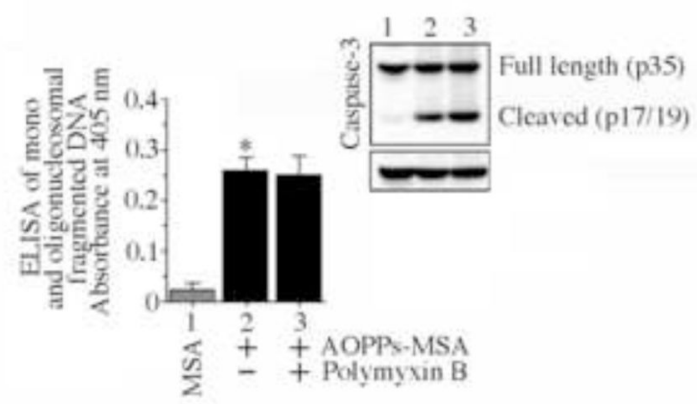

$\mathrm{F}$

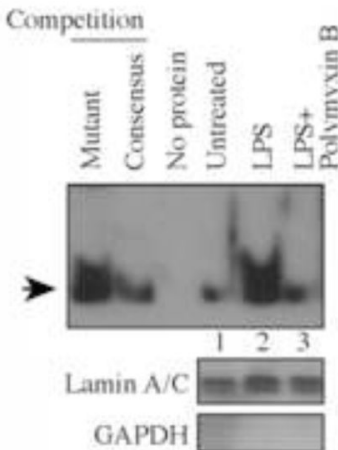

Fig 1. AOPPs-MSA induces neonatal and adult mouse cardiomyocyte death A, Neonatal mouse cardiomyocytes (NMCM) were treated with increasing concentrations of AOPPs-MSA for $24 \mathrm{~h}$. Unmodified MSA at $100 \mu \mathrm{g} / \mathrm{ml}$ served as the control. Mono and oligonucleosomal fragmented DNA in cytoplasmic extracts was quantified by a cell death ELISA. $* P<$ at least 0.01 versus MSA $(\mathrm{n}=12) . B$, AOPPs-MSA induces nucleosomal DNA fragmentation (DNA laddering). NMCM were treated as in $A$ with AOPPs-MSA (50 $\mu \mathrm{g} / \mathrm{ml}$ ) for $18 \mathrm{~h}$. Genomic DNA was isolated and equal amounts were electrophoresed in $1 \%$ agarose gel, visualized by ethidium bromide staining, and photographed. MSA at $50 \mu \mathrm{g} / \mathrm{ml}$ served as a control. Ladder: $100 \mathrm{bp}$. A representative of three independent experiments is shown. $C$, The effect of AOPPs-MSA $(50 \mu \mathrm{g} / \mathrm{ml})$ on cardiomyocyte viability was determined by the MTT assay. ${ }^{*} P<0.001$ versus untreated or MSA $(\mathrm{n}=12) . D$, AOPPsMSA activates caspase-3. NMCM treated with AOPPs-MSA $(50 \mu \mathrm{g} / \mathrm{ml}$ for $8 \mathrm{~h})$ were analyzed for caspase- 3 activity by a fluorescent method, and the active form of caspase-3 (p17) in whole cell lysates determined by immunoblotting (inset; $\mathrm{n}=3$ ). ${ }^{*} P<0.001$ versus MSA (n=12/group). E, Polymyxin B fails to modulate AOPPs-MSA induced NMCM death. NMCM were treated with AOPPs-MSA, and analyzed for caspase- 3 activation by immunoblotting ( $8 \mathrm{~h}$; inset) and cell death $(24 \mathrm{~h})$ as in $A$ by ELISA. $F$, Polymyxin B inhibits LPS-induced NF- $\kappa B$ activation. Quiescent NMCM were incubated with polymyxin B (10 $\mu \mathrm{g} / \mathrm{ml}$ for $10 \mathrm{~min})$ prior to LPS addition $(0.5 \mu \mathrm{g} / \mathrm{ml}$ for $2 \mathrm{~h})$. NF- $\mathrm{\kappa B}$ DNA binding activity was analyzed by EMSA using nuclear protein extracts and ${ }^{32} \mathrm{P}$-labeled double-stranded NF$\kappa B$ consensus oligonucleotides. Specificity of DNA binding was verified in competition experiments. Arrow denotes NF-кB-specific DNA-protein complexes. Unbound labeled probe at the bottom of gel is not shown. Lamin A/C (nuclear) and GAPDH (cytoplasmic) served as loading and purity controls, and are shown in the bottom panel. 
A

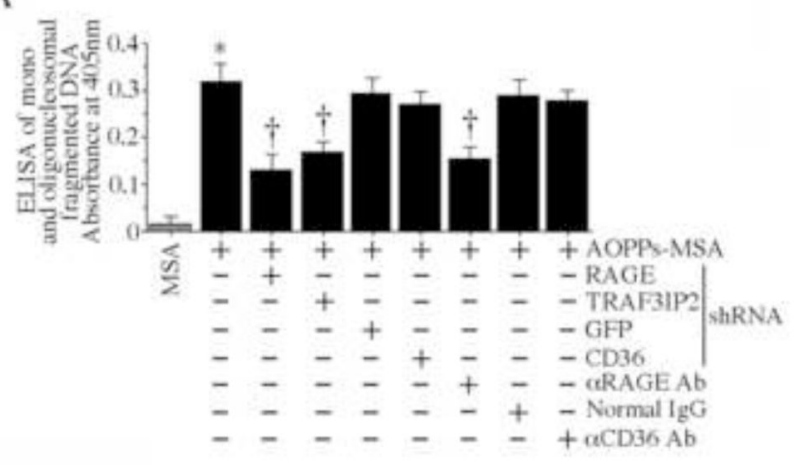

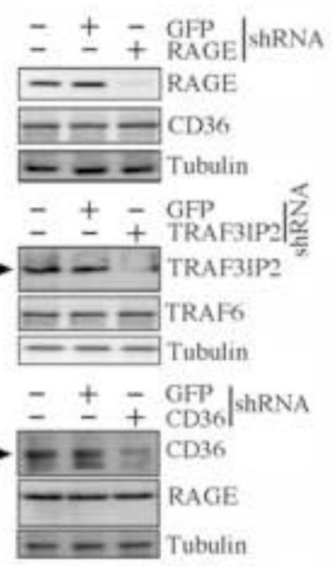

B

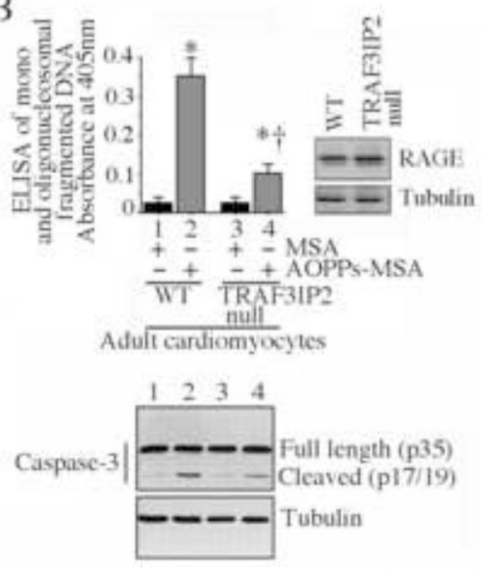

Fig. 2. AOPPs-MSA induces cardiomyocyte death via RAGE and TRAF3IP2 $A, \mathrm{NMCM}$ were infected with lentiviral shRNA for RAGE, CD36 or TRAF3IP2 (MOI 0.5 for $48 \mathrm{~h})$, or incubated with antibodies against RAGE or CD36 $(20 \mu \mathrm{g} / \mathrm{ml}$ for $2 \mathrm{~h})$ prior to the addition of AOPPs-MSA ( $50 \mu \mathrm{g} / \mathrm{ml}$ for $24 \mathrm{~h}$ ). Knockdown of target and not the offtarget proteins was confirmed by immunoblotting and is shown on the right. Cell death was determined as in Fig. $1 A . * P<0.001$ versus MSA, $\dagger P<$ at least 0.01 versus AOPPs-MSA \pm GFP or control IgG (n=12/group). $B$, AOPPs-MSA induced adult mouse cardiomyocyte death is markedly attenuated by TRAF3IP2 gene deletion. Cardiomyocytes isolated from 12 week-old male WT C57Bl/6 or TRAF3IP2 null mice were incubated with AOPPs-MSA (50 $\mu \mathrm{g} / \mathrm{ml}$ for $24 \mathrm{~h}$ ). Cell death was determined as in Fig. $1 A$. Basal expression of RAGE was analyzed by immunoblotting using cleared whole cell homogenates (right hand panel). Caspase- 3 activation was analyzed by immunoblotting (lower panel, $\mathrm{n}=3$ ). $* P<$ at least 0.05 versus respective MSA-treated, $\uparrow P<0.01$ versus AOPPs-MSA treated WT cardiomyocytes ( $\mathrm{n}=12 /$ group). 
A

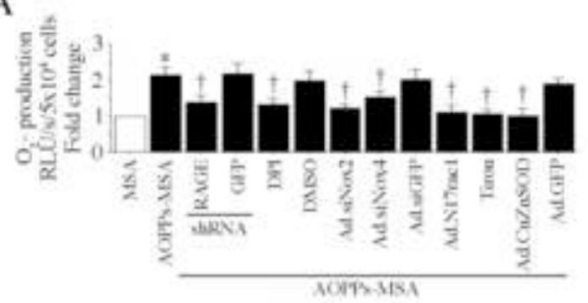

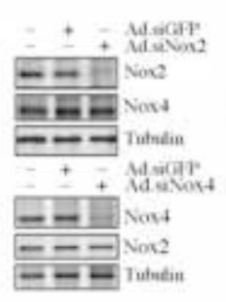

B
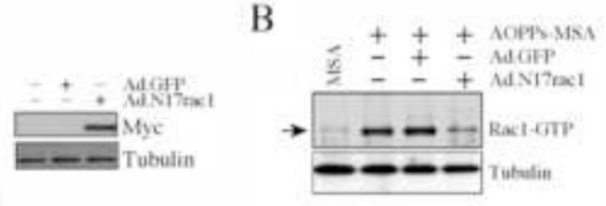

C

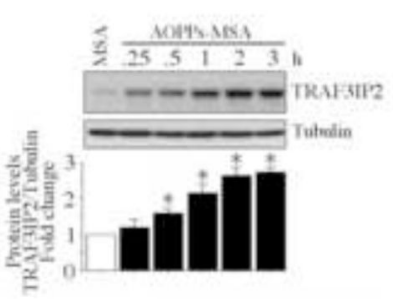

D

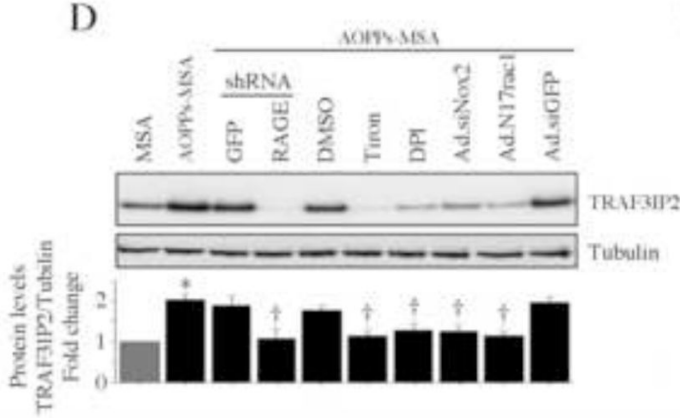

$\mathrm{E}$

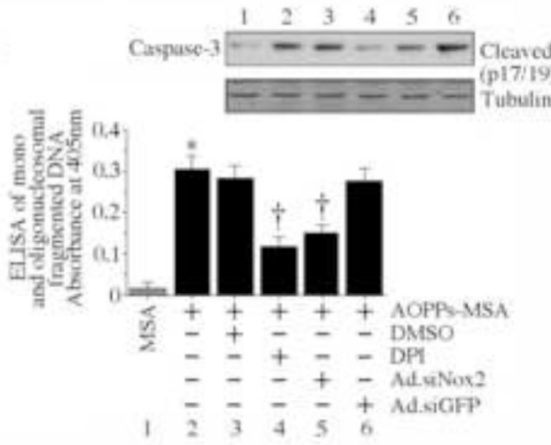

Fig. 3. AOPPs-MSA induces TRAF3IP2 expression via Nox2-dependent ROS generation $A$, AOPPs-MSA induces superoxide generation in NMCM. NMCM loaded with darkadapted lucigenin $(5 \mu \mathrm{M})$ were incubated with AOPPs-MSA $(50 \mu \mathrm{g} / \mathrm{ml})$ alone or AOPPsMSA with DPI (10 $\mu \mathrm{M}$ in DMSO for $30 \mathrm{~min}$ ) or Tiron (5 $\mathrm{mM}$ for $1 \mathrm{~h})$. DMSO served as a solvent control. Studies were also performed using NMCM transduced with RAGE lentiviral shRNA particles (MOI 0.5 for 48 h), or infected with Ad.siNox2, Ad.siNox4, Ad.N17rac1 (MOI 100 for $48 \mathrm{~h}$ ), or Ad.CuZnSOD (MOI 100 for $24 \mathrm{~h}$ ) prior to AOPPs-MSA addition. Superoxide $\left(\mathrm{O}_{2}^{-}\right)$production was quantified using the lucigenin-enhanced chemiluminescence assay. Luminescence was measured for $10 \mathrm{~s}$ with a delay of $5 \mathrm{~s}$. After subtracting background luminescence, results (RLU/second/5x $10^{4}$ cells) are expressed as fold increase from untreated controls. The knockdown of target and not the off-target proteins was confirmed by immunoblotting and is shown on the right. Myc expression from $\mathrm{N} 17 \mathrm{rac} 1$ is confirmed by immunoblotting, and is also shown on the right. $* P<$ at least 0.01 versus $\mathrm{MSA}, \dagger P<$ at least 0.05 versus AOPPs-MSA \pm respective controls $(\mathrm{n}=12) . B$, AOPPs-MSA-stimulated Rac1 activity is blunted by Ad. N17rac1. NMCM infected with Ad.N17rac1 were treated with AOPPs-MSA $(50 \mu \mathrm{g} / \mathrm{ml})$. Rac1 activity was analyzed at 30 $\min (\mathrm{n}=3) . C$, AOPPs-MSA induces time-dependent TRAF3IP2 expression. NMCM were treated with AOPPs-MSA $(50 \mu \mathrm{g} / \mathrm{ml})$ for the indicated time periods. TRAF3IP2 expression was analyzed by immunoblotting using cleared whole cell lysates. The intensity of immunoreactive bands was semi-quantified by densitometry, and the results from three independent experiments are summarized in the lower panel. $* P<$ at least 0.05 versus MSA. $D$, AOPPs-MSA induces TRAF3IP2 expression via Nox2/Rac1/ROS. NMCM treated as in $A$, but for $1 \mathrm{~h}$, were analyzed for TRAF3IP2 expression by immunoblotting $(\mathrm{n}=3) . E$, AOPPs-MSA induces cell death via ROS and Nox2. NMCM were infected with Ad.siNox2 (MOI 100 for $48 \mathrm{~h}$ ) or treated with DPI (10 $\mu \mathrm{M}$ in DMSO for $30 \mathrm{~min}$ ) prior to the addition of AOPPs-MSA $(50 \mu \mathrm{g} / \mathrm{ml}$ for $24 \mathrm{~h})$. Cell death was analyzed as in Fig. $1 A$. In parallel experiments, caspase- 3 activation was analyzed at $8 \mathrm{~h}$ by immunoblotting $(\mathrm{n}=3)$. ${ }^{*} P<0.001$ versus MSA-treated, $\uparrow P<$ at least 0.01 versus AOPPs-MSA \pm respective controls $(\mathrm{n}=12 /$ group). 
A

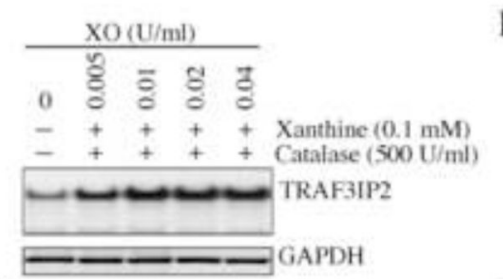

B

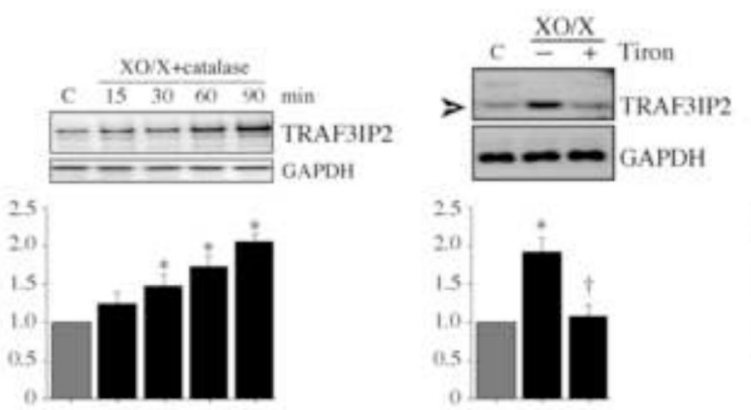

C

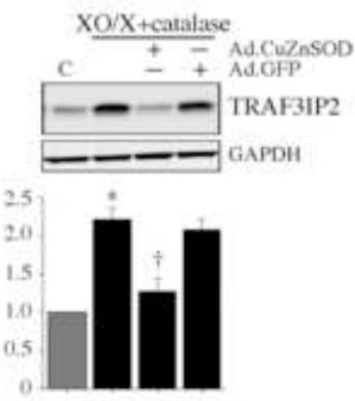

D

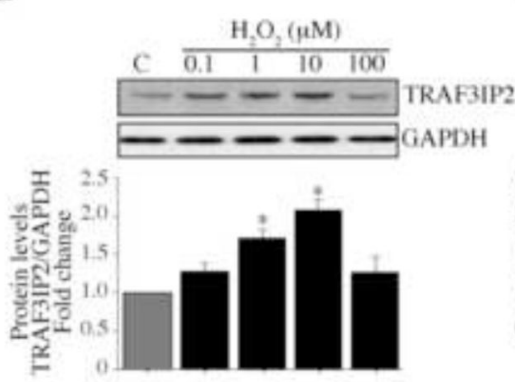

E

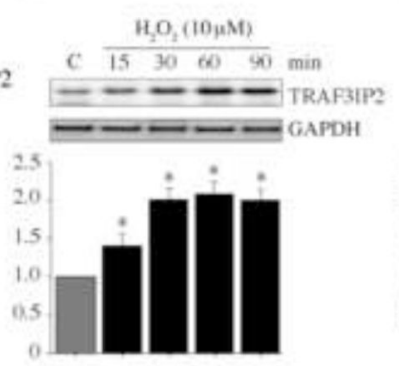

F

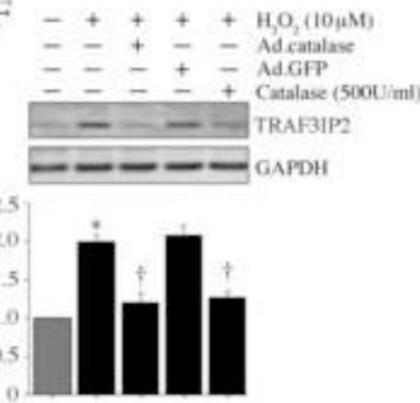

G

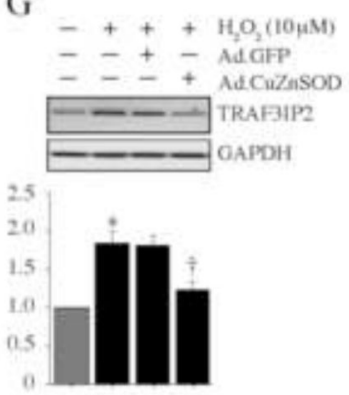

Fig. 4. ROS induce TRAF3IP2 expression $A$, Superoxide induces TRAF3IP2 expression. NMCM were incubated with xanthine (X; 0.1 $\mathrm{mM}$ ) and increasing concentrations of xanthine oxidase (XO) in the presence of catalase (500 units/ml) for $1 \mathrm{~h}$. TRAF3IP2 expression was analyzed by immunoblotting $(\mathrm{n}=3) . B, \mathrm{X} /$ $\mathrm{XO}$ induces time-dependent TRAF3IP2 expression. NMCM were treated as in $A$ with X $(0.01 \mathrm{mM}), \mathrm{XO}(0.005 \mathrm{U} / \mathrm{ml})$, and catalase $(500 \mathrm{U} / \mathrm{ml})$ for the indicated time periods. TRAF3IP2 expression was analyzed by immunoblotting $(\mathrm{n}=3)$. $C$, CuZnSOD blocks X/XO induced TRAF3IP2 expression. NMCM were infected with Ad.CuZnSOD (MOI 100 for 24 h) prior to $\mathrm{X} / \mathrm{XO} /$ catalase addition as in B. After $1 \mathrm{~h}$, TRAF3IP2 expression was analyzed by immunoblotting $(\mathrm{n}=3)$. $D$, Hydrogen peroxide induces TRAF3IP2 expression. NMCM were treated with $\mathrm{H}_{2} \mathrm{O}_{2}$ at the indicated doses. TRAF3IP2 expression was analyzed after $1 \mathrm{~h}$ by immunoblotting $(\mathrm{n}=3) . E, \mathrm{H}_{2} \mathrm{O}_{2}$ induces time-dependent TRAF3IP2 expression. NMCM were treated with $\mathrm{H}_{2} \mathrm{O}_{2}(10 \mu \mathrm{M})$ for the indicated time periods. TRAF3IP2 expression was analyzed by immunoblotting $(\mathrm{n}=3) . F, \mathrm{H}_{2} \mathrm{O}_{2}$ induced TRAF3IP2 expression is blocked by catalase. NMCM treated for $1 \mathrm{~h}$ simultaneously with $\mathrm{H}_{2} \mathrm{O}_{2}$ and catalase $(500 \mathrm{U} / \mathrm{ml})$ or treated with $\mathrm{H}_{2} \mathrm{O}_{2}(10 \mu \mathrm{M}$ for $1 \mathrm{~h})$ after $24 \mathrm{~h}$ infection with Ad.catalase (MOI 100) were analyzed for TRAF3IP2 expression by immunoblotting (n=3). $G$, CuZnSOD blocks $\mathrm{H}_{2} \mathrm{O}_{2}$ induced TRAF3IP2 expression. NMCM infected with Ad.CuZnSOD (MOI 100 for $24 \mathrm{~h}$ ) were incubated with $\mathrm{H}_{2} \mathrm{O}_{2}(10 \mu \mathrm{M})$ for $1 \mathrm{~h}$, and then analyzed for TRAF3IP2 expression by immunoblotting $(n=3)$. 
A

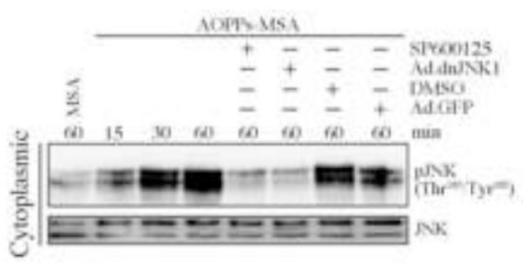

B

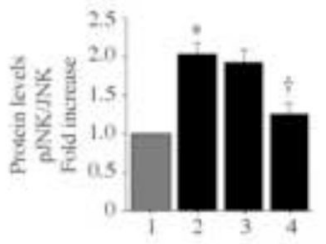

$\mathrm{C}$

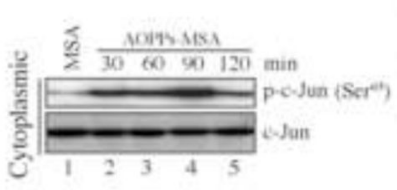

E
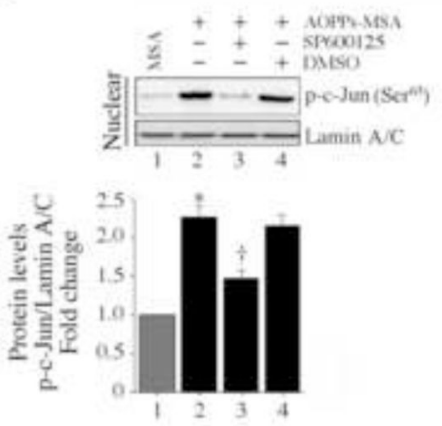

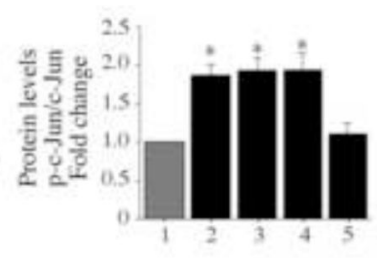

$\mathrm{F}$

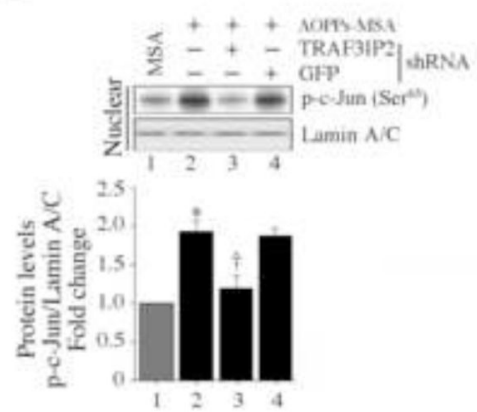

D
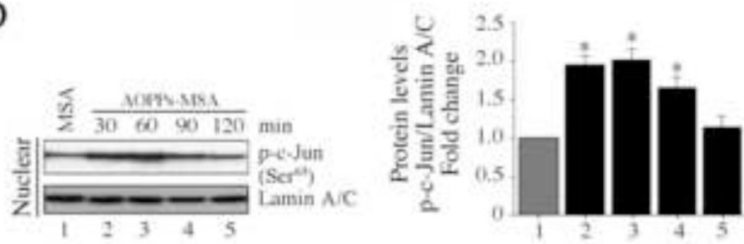

G

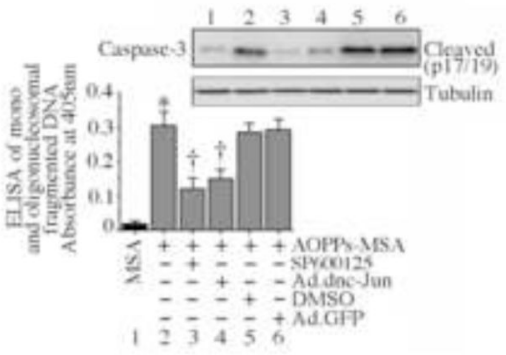

Fig. 5. AOPPs-MSA induces cardiomyocyte death via TRAF3IP2/JNK/c-Jun $A$, AOPPs-MSA induces time-dependent JNK activation, and is inhibited by the JNK inhibitor SP600125 and dnJNK1. NMCM were treated with SP600125 (20 $\mu \mathrm{M}$ for $30 \mathrm{~min})$ or infected with Ad.dnJNK1 (MOI 100 for $24 \mathrm{~h}$ ) prior to AOPPs-MSA $(50 \mu \mathrm{g} / \mathrm{ml})$ addition. Total and phospho-JNK (The183/Tyr185) levels were analyzed by immunoblotting $(n=3)$. $B$, TRAF3IP2 knockdown blunts AOPPs-MSA-induced JNK phosphorylation. NMCM infected with TRAF3IP2 shRNA or control lentivirus (MOI 0.5 for $48 \mathrm{~h}$ ) were exposed to AOPPs-MSA $(50 \mu \mathrm{g} / \mathrm{ml}$ for $1 \mathrm{~h})$. Phospho-JNK levels were analyzed by immunoblotting as in $A(n=3)$. $C$, AOPPs-MSA induces time-dependent c-Jun phosphorylation. NMCM treated with AOPPs-MSA $(50 \mu \mathrm{g} / \mathrm{ml})$ for the indicated time were analyzed for total and phospho-c-Jun by immunoblotting using whole cell lysates $(\mathrm{n}=3)$. $D$, AOPPs-MSA promotes time-dependent c-Jun nuclear translocation. NMCM treated as in $C$ were analyzed for phospho-c-Jun (Ser63) levels in nuclear protein extracts (n=3). E, JNK inhibition blocks c-Jun nuclear translocation. NMCM treated with SP600125 (20 $\mu \mathrm{M}$ for $30 \mathrm{~min})$ prior to AOPPs-MSA addition ( $50 \mu \mathrm{g} / \mathrm{ml}$ for $30 \mathrm{~min}$ ) were analyzed for phospho-c-Jun levels in nuclear protein extracts as in $D(\mathrm{n}=3)$. $F$, TRAF3IP2 knockdown blunts AOPPs-MSAinduced c-Jun nuclear translocation. NMCM treated as in $B$, but for 30 min, were analyzed for phospho-c-Jun levels in nuclear protein extracts $(\mathrm{n}=3)$. $G$, JNK inhibition blocks AOPPsMSA induced cardiomyocyte death. NMCM treated with SP600125 (20 M for $30 \mathrm{~min}$ ) or infected with Ad.dnJNK1 (MOI 100 for $24 \mathrm{~h}$ ) were treated with AOPPs-MSA $(50 \mu \mathrm{g} / \mathrm{ml})$ for 8 or $24 \mathrm{~h}$, and then analyzed for caspase-3 activation at $8 \mathrm{~h}$ by immunoblotting and cell death as in Fig. $1 A$ by ELISA. $* P<0.001$ versus MSA, $\dagger P<0.01$ versus AOPPs-MSA \pm respective controls $(\mathrm{n}=12)$. 

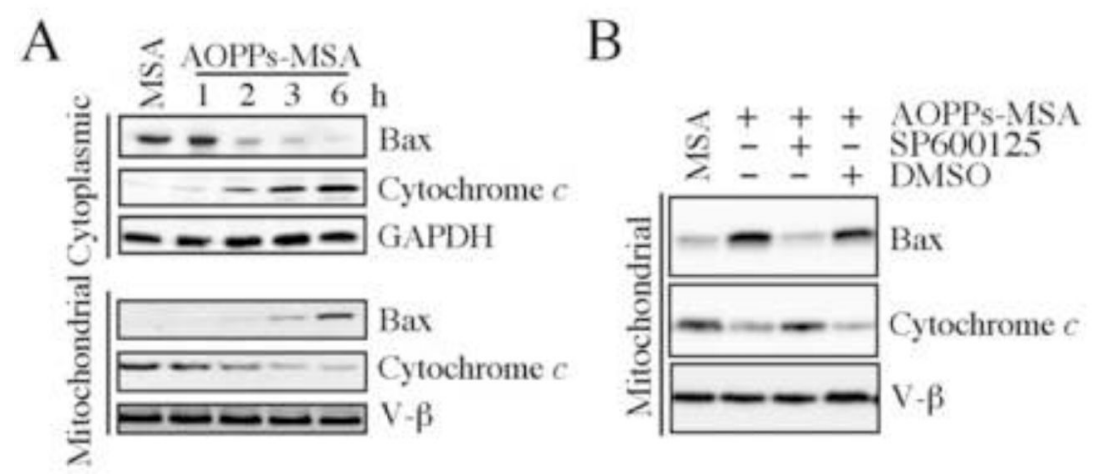

C

D

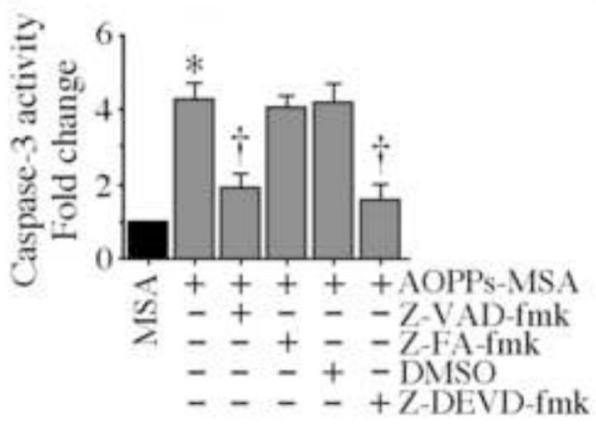

E

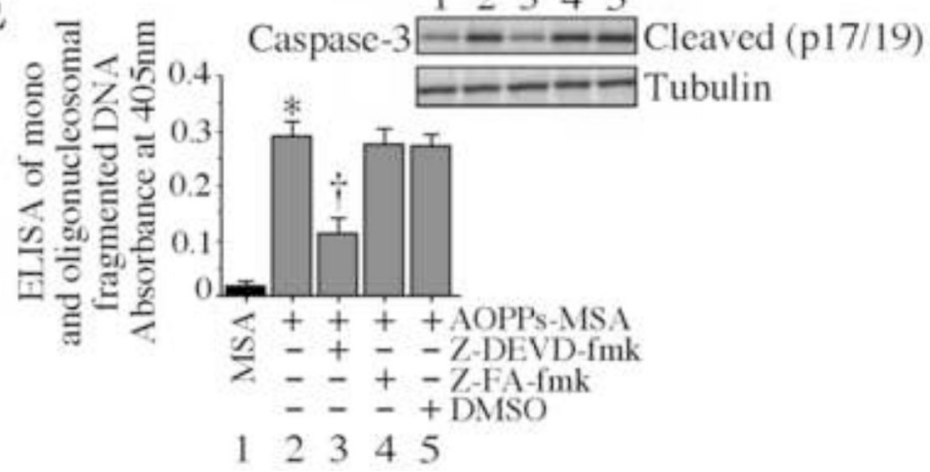

Fig. 6. AOPPs-MSA activates pro-apoptotic signaling in cardiomyocytes $A$, AOPPs-MSA promotes Bax translocation to mitochondria and stimulates cytochrome $c$ release into cytoplasm. NMCM were treated with AOPPs-MSA $(50 \mu \mathrm{g} / \mathrm{ml})$ for the indicated time periods. Mitochondrial and cytoplasmic extracts were analyzed for Bax and cytochrome $c$ levels by immunoblotting. Purity of extracts and equal loading were verified by GAPDH (cytoplasmic) and V- $\beta$ (mitochondrial) expressions by immunoblotting $(\mathrm{n}=3)$. $B$, JNK inhibition reverses AOPPs-MSA induced mitochondrial Bax expression and cytochrome $c$ release. NMCM treated with SP600125 (20 $\mu \mathrm{M}$ for $30 \mathrm{~min}$ ) prior to AOPPsMSA addition $(50 \mu \mathrm{g} / \mathrm{ml}$ for $6 \mathrm{~h}$ ) were analyzed for Bax and cytochrome $c$ levels in the mitochondrial fraction $(\mathrm{n}=3)$. $C$, JNK inhibition blunts AOPPs-MSA-induced cytochrome $c$ release. NMCM treated as in $B$ were analyzed for cytochrome c levels in cytoplasm. Purity of cytoplasmic extracts and equal loading were confirmed by immunoblotting for GAPDH (cytoplasmic) and V- $\beta$ (mitochondrial) (inset). $* P<0.001$ versus MSA, $\dagger P<0.01$ versus AOPPs-MSA (n=6/group). $D$, AOPPs-MSA activates caspase-3. NMCM were treated with caspase-3 (Z-DEVD-fmk) or pan-caspase (Z-VAD-fmk) inhibitor (50 $\mu \mathrm{M}$ in DMSO for 30 min) prior to AOPPs-MSA addition $(50 \mu \mathrm{g} / \mathrm{ml}$ for $8 \mathrm{~h})$. Z-FA-fmk served as a negative control. DMSO served as a solvent control. Caspase- 3 activity was analyzed by a fluorescent method. $* P<0.001$ versus MSA, $\dagger P<0.01$ versus AOPPs-MSA (n=6/group). $E$, Caspase-3 inhibition blunts AOPPs-MSA-induced NMCM death. NMCM treated as in $D$, but for 8 or $24 \mathrm{~h}$ were analyzed for caspase- 3 activation by immunoblotting $(\mathrm{n}=3)$ and cell death by ELISA. $* P<0.001$ versus MSA, $\dagger P<0.01$ versus AOPPs-MSA (n=12/group). 


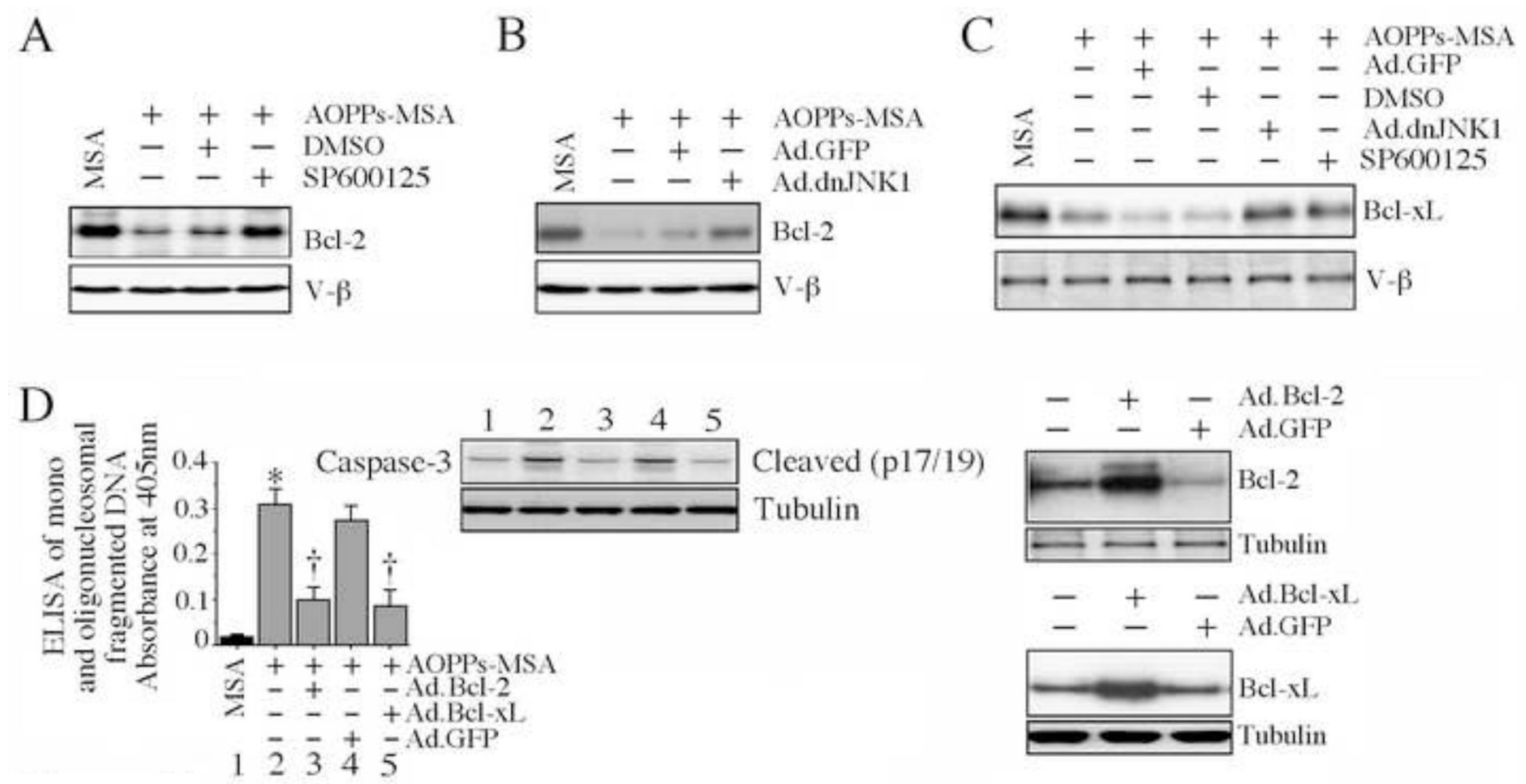

Fig. 7. AOPPs-MSA suppresses anti-apoptotic signaling via JNK activation $A, B$, Inhibition of JNK reverses AOPPs-MSA induced Bcl-2 suppression. NMCM treated with SP600125 ( $A ; 20 \mu \mathrm{M}$ for $30 \mathrm{~min})$ or infected with Ad.dnJNK1 (B; MOI 100 for $24 \mathrm{~h})$ were exposed to AOPPs-MSA (50 $\mu \mathrm{g} / \mathrm{ml}$ for $6 \mathrm{~h})$. Bcl-2 levels in whole cell lysates were analyzed by immunoblotting $(n=3)$. $C$, Inhibition of JNK reverses AOPPs-MSA induced Bcl-xL suppression. NMCM treated as in A were analyzed for Bcl-xL levels in whole cell lysates by immunoblotting $(n=3)$. $D$, Forced expression of wild-type Bcl-2 or Bcl-xL inhibits AOPPs-MSA induced caspase-3 activation and cell death. NMCM transfected with Ad.Bcl-2 or Ad.Bcl-xL (MOI 100 for $24 \mathrm{~h}$; expression levels of Bcl-2 and Bcl-xL following transduction are shown on the right; $\mathrm{n}=3)$ were treated with AOPPs-MSA $(50 \mu \mathrm{g} / \mathrm{ml}$ for 8 or $24 \mathrm{~h})$. Caspase-3 activation was analyzed by immunoblotting $(\mathrm{n}=3)$. Cell death was analyzed by ELISA. $* P<0.001$ versus MSA, $\dagger P<$ at least 0.001 versus AOPPs-MSA \pm Ad.GFP ( $\mathrm{n}=12$ /group). 